\title{
Aporte de serapilheira na borda de fragmentos florestais em diferentes estágios sucessionais na Mata Atlântica do Rio Grande do Norte, Brasil
}

\author{
Assessment of litterfall in the edge of forest fragments at different \\ successional stages in the Atlantic Forest of Rio Grande do Norte, Brazil \\ Yasmim Borges Câmaral', Alan Cauê de Holanda² e Emanoelle Josephine Pereira da Costa'
}

\begin{abstract}
1 Universidade Federal do Rio Grande do Norte. Unidade Acadêmica Especializada em Ciências Agrárias. Programa de Pós-Graduação em Ciências
\end{abstract} Florestais. Natal, Rio Grande do Norte, Brasil.

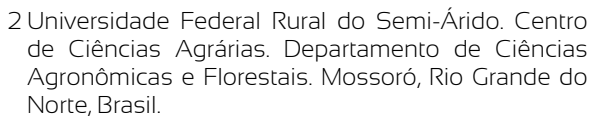

* Autor correspondente: alan.holanda@aufersa.edu.br

\section{Autor correspondente: alan.holanda@aufersa.edu.br}

\section{RESUMO}

A serapilheira é a camada mais superficial do piso florestal e analisar sua deposição é fundamental para avaliar a estabilidade de uma das principais rotas da ciclagem de nutrientes em fragmentos florestais. O objetivo do trabalho foi avaliar o aporte de serapilheira na borda de três fragmentos florestais de Mata Atlântica, em diferentes estágios de sucessão (transitório e maduro), localizados na Floresta Nacional de Nísia Floresta (Rio Grande do Norte, Brasil). Foram instalados 54 coletores, 18 em cada fragmento, distanciados de 0 m a $100 \mathrm{~m}$ em relação à borda e, mensalmente, durante 12 meses, foram coletados todo o material aportado. $\mathrm{O}$ material foi seco em estufa a $65^{\circ} \mathrm{C}$ por $48 \mathrm{~h}$ e pesado em balança de precisão. A deposição anual total no gradiente borda interior foi de 3227,90 kg ha-1 (fragmento I), 3315,60 $\mathrm{kg} \mathrm{ha}^{-1}$ (fragmento II) e 1775,90 $\mathrm{kg} \mathrm{ha}^{-1}$ (fragmento III). Somente para o fragmento III foi verificado diferenças estatísticas no aporte de serapilheira da borda para o interior com valores variando entre 93,87 $\mathrm{kg} \mathrm{ha}^{-1} \mathrm{ano}^{-1}$ (borda) a 261,7 kg ha-1 ano $\mathrm{kg}^{-1}(100 \mathrm{~m}$ ). O maior aporte no fragmento II se deu, a princípio, em razão da diversidade de espécies e maior porte dos indivíduos adultos. O aporte de serapilheira teve comportamento sazonal apresentando maior deposição no período seco, indicando que a pluviosidade atua como agente regulador desse material. Além disso, a borda de fragmentos florestais em estágio inicial de sucessão tende a depositar menor quantidade de serapilheira no piso florestal.

PALABRAS CLAVE: ciclagem de nutrientes, efeito de borda, fragmentação, unidade de conservação.

\section{ABSTRACT}

Litter is the most superficial layer of the forest floor, and analyzing its deposition is essential to assess the stability of one of the main routes of nutrient cycling in forest fragments. The objective of this work was to evaluate the litter input on the edge of three forest fragments in different succession stages (transitional and mature) located in the Floresta Nacional de Nísia Floresta (Rio Grande do Norte, Brasil). 54 collectors were installed, 18 in each fragment, spaced from $0 \mathrm{~m}$ to $100 \mathrm{~m}$ in relation to the edge and, monthly, for 12 months, all the litterfall was collected. The material was oven-dried at $65{ }^{\circ} \mathrm{C}$ for 48 hours and weighed on a precision scale. The estimated annual deposition in the internal edge gradient was 3227,90 kg ha-1 (fragment I), 3315,60 kg ha-1 (fragment II) and 1775,90 kg ha ${ }^{-1}$ (fragment III). Only for fragment III, there were statistical differences in the total input of dead organic matter from the edge to the interior, with values ranging from $93,87 \mathrm{~kg} \mathrm{ha}^{-1}$ year $^{-1}$ (edge) to $261,7 \mathrm{~kg} \mathrm{ha}^{-1}$ year $^{-1}(100 \mathrm{~m})$. The largest amount of organic material in fragment II was, at first, due to the diversity of species and the larger size of adult individuals. The litter input had a seasonal behavior, showing greater deposition in the adverse period, indicating that rainfall acts as a regulating agent for such material. In addition, the edge of forest fragments at an early stage of succession tends to deposit less litter on the forest floor.

KEYWORDS: nutrient cycling, edge effect, fragmentation, conservation unit. 


\section{INTRODUÇÃO}

A presença de serapilheira no solo é fundamental para a manutenção do ecossistema e para regulação da sustentabilidade florestal, pois é capaz de promover o aumento da capacidade de retenção de água no solo, facilitando o desenvolvimento das plantas, e consequentemente a redução do escoamento de água superficial, evitando a erosão (Conceição, Amado, Mielniczuk e Spagnollo, 2005). Esse conteúdo é formado por todo material orgânico depositado no solo na forma de resíduos vegetais e animais, biomassa microbiana, meso e macrofauna (Barreto, 2014). Além de que, exerce influência sobre as condições do meio, promovendo a ciclagem de nutrientes e possibilitando a formação de um microclima (Cunha Neto, Leles, Pereira, Bellumath e Alonso, 2013).

A serapilheira é um dos principais estoques e rotas de nutrientes em um ambiente florestal, porém, sua deposição e decomposição sofre interferências de diversos fatores bióticos a abióticos, como a fragmentação associada ao surgimento de novas bordas. A expansão de fronteiras agrícolas por exemplo é uma das principais causas da fragmentação, ocasionando o rompimento de um contínuo florestal. Com isso, novas bordas se formam expondo espécies adaptadas a fatores abióticos do interior da floresta a condições adversas, podendo provocar o aumento da evapotranspiração e influenciando negativamente na dinâmica dos fragmentos florestais (Holanda et al., 2010).

Para Ribeiro (2008), ao longo do tempo esses fragmentos tendem a apresentar uma redução de sua biodiversidade e, conforme Blumenfeld, Santos, Thomaziello e Ragazzi (2016) a formação da borda permite a atuação dos componentes externos, bióticos e abióticos, que modificam a paisagem de maneira abrupta e comprometem a biodiversidade autóctone. Em um fragmento florestal recém formado, fatores como, histórico de perturbação, tipo de vizinhança, área do fragmento, grau de isolamento, forma do fragmento e efeito de borda, interferem de formas distinta em vários processos dinâmicos nos fragmentos (Viana, Tabanez e Martins, 1992). Assim, cabe analisar, dentre vários indicadores, como o histórico de perturbação, através do estágio sucessional de diferentes fragmentos, promovem o aporte de serapilheira.

Dessa forma, há necessidade de compreender parte de um conjunto complexo e dinâmico, processos que envolvem a matéria orgânica do solo, considerando os diferentes estágios sucessionais presentes nas bordas de fragmentos florestais, como também os graus de perturbação, avaliando a forma como incidem em diversos indicadores ambientais, com intuito de obter futuras medidas mitigadoras que atendam o uso sustentável, minimizando possíveis impactos (Franco e Campello, 1997).

\section{OBJETIVOS}

O objetivo do trabalho foi avaliar o aporte de serapilheira na borda de três fragmentos florestais de Mata Atlântica em diferentes estágios sucessionais, localizados na Floresta Nacional de Nísia Floresta, estado do Rio Grande do Norte.

\section{MATERIAL E MÉTODOS}

\section{Caracterização da área}

O trabalho foi conduzido na Floresta Nacional de Nísia Floresta (Flona), localizada no município de Nísia Floresta, $\mathrm{RN}$, inserida entre as coordenadas $06^{\circ} 05^{\prime} 12,4^{\prime}$ ' S e $35^{\circ} 11^{\prime}$ 0,40" W. Possui uma área de 174,95 ha, relevo plano e altitude inferior a $30 \mathrm{~m}$. O clima é tropical, classificado como Aw segundo Köppen-Geiger com variação de temperatura entre $20^{\circ} \mathrm{C}$ e $27^{\circ} \mathrm{C}$. A precipitação média anual é de $1455 \mathrm{~mm}$, com umidade relativa média de 76\% (Alvares, 2014). O solo é classificado como Latossolo Vermelho-Amarelo, álico, com textura média (Radam Brasil, 1981). A vegetação da Flona é caracterizada como Floresta Estacional Semidecidual, sob o domínio do bioma Mata Atlântica (Instituto Brasileiro de Geografia e Estatística [IBGE], 2012).

A Flona encontra-se em uma região historicamente explorada pela monocultura da cana-de-açúcar, onde após a década 1970 foram implantados experimentos com espécies florestais. Devido ao histórico de interferência 
antrópica, não existe comunidade florestal primária no seu interior, a sua atual fisionomia e composição florística é constituída por áreas alteradas em estágio de regeneração e áreas de experimentação florestal (Ministério do Meio Ambiente, 2012).

Conforme observações coletadas em estudo fitossociológico realizado por Oliveira, Santos Júnior, Feliciano, Marangon e Carvalho (2001), a área da Flona foi dividida em diferentes subáreas (I, II, III e IV). Dentre as respectivas áreas, optou-se por escolher dois fragmentos na subárea IV (Fragmento I e II) considerado maduros, pois a preservação ocorre anterior ao ano 1950, apresentando estágio mais avançado de regeneração, e outro na área II, que é de plantio experimental (Fragmento III) referente a uma área abandonada pela atividade canavieira até a década de 1970, sendo substituída por plantios experimentais e posteriormente abandonada.

\section{Coleta dos dados}

Para avaliar o aporte de serapilheira, 18 coletores foram instalados em cada fragmento em junho de 2018, totalizando 54 coletores. O Fragmento I, em estágio mais avançado de sucessão (clímax), possui uma área de 42,7 ha, com 594 m de distância do Fragmento II. O Fragmento II, com estágio transicional entre intermediário e clímax, possui uma área de 36,2 ha, distando $504 \mathrm{~m}$ do Fragmento III. O terceiro Fragmento, em estágio sucessional efêmero, quando comparado aos fragmentos I e II, abrange uma área de 17 ha e está distante 995 m do Fragmento I.

Em cada fragmento os coletores foram distribuídos sistematicamente em seis faixas de distância da borda $(0 \mathrm{~m}$, 20 m, 40 m, 60 m, 80 m e 100 m). Dentro de cada uma das faixas foram instalados 3 coletores em linha, com distância de $10 \mathrm{~m}$ entre si. Os coletores foram confeccionados em rede de tela de nylon ( $1 \mathrm{~mm}$ ), com formato circular, área de $0,159 \mathrm{~m}^{2}$ e $40 \mathrm{~cm}$ de profundidade, sustentado por canos de PVC de $1 \mathrm{~m}$, sendo fixados a aproximadamente $0,80 \mathrm{~m}$ de altura do solo.

Esses coletores foram monitorados mensalmente, sempre na primeira semana de cada mês, durante um ano, de julho de 2018 a junho de 2019, com intuito de quantificar o volume de material aportado nesses fragmentos. Após coletado, o material foi seco ao ar livre por 3 dias, em seguida foi acondicionado em sacos de papel devidamente identificados e levado para estufa a $65^{\circ} \mathrm{C}$, permanecendo por pelo menos 48 horas.

Para quantificação do material foi utilizada a seguinte equação matemática:

$$
P A S=\frac{(P S * 10000)}{A C}
$$

Em que:

$\mathrm{PAS}=$ produção média anual de serapilheira $\left(\mathrm{kg} \mathrm{ha}^{-1} \mathrm{ano}^{-1}\right)$ PS $=\quad$ produção média mensal de serapilheira $\left(\mathrm{kg} \mathrm{ha}^{-1}\right.$ mês $\left.^{-1}\right)$ $10000=$ um hectare expresso $\left(\mathrm{m}^{2}\right)$

Ac $=$ área do coletor $\left(\mathrm{m}^{2}\right)$

\section{Análise dos dados}

Após as atividades no laboratório, os valores obtidos nas pesagens foram tabulados no software Microsoft Excel(C) onde foram geradas planilhas com os resultados mensais. As médias obtidas para as variáveis foram comparadas pelo teste de Scott-Knott com nível de significância de 5\%, e o software utilizado foi o SISVAR versão 5.3. A partir da elaboração de matrizes, aplicou-se a análise de agrupamento, utilizando como medida de similaridade a distância euclidiana para se entender a dinâmica do aporte do material em relação a borda para o interior de cada fragmento. O software utilizado foi o Statistica ${ }^{\circledR} 7$.

\section{Resultados E DISCUSSÃo}

Foi estimado uma deposição de serapilheira total na borda dos fragmentos ( $0 \mathrm{~m}-100 \mathrm{~m})$ de 3227,9; 3315,6 e 1775,9 $\mathrm{kg} \mathrm{ha}^{-1} \mathrm{ano}^{-1}$ para os fragmentos I, II e III, respectivamente (Tabela 1). Para o fragmento I, a maior e menor taxa de deposição foram registradas nos meses de outubro (2018) e maio (2019), com 536,72 kg ha-1 e 85,01 kg ha-1, respectivamente. Para os fragmentos II e III, o maior e menor aporte estimado foram nos meses novembro (2018) e junho (2019) com estimativa de 782,79 $\mathrm{kg} \mathrm{ha}^{-1}$ e 66,32 kg $\mathrm{ha}^{-1}$ e, 478,04 kg ha-1 e 69,30 $\mathrm{kg} \mathrm{ha}^{-1}$, respectivamente. 
TABELA 1. Estimativa total da deposição de serapilheira na borda (0 m-100 m) dos três fragmentos florestais localizados na Flona de Nísia Floresta, RN.

\begin{tabular}{|c|c|c|c|c|}
\hline Ano & Mês & Fragmento I & Fragmento II & Fragmento III \\
\hline \multirow{4}{*}{2018} & Julho & 213,10 aA & 200,39 aA & 103,85 aA \\
\hline & Agosto & 244,26 aA & 182,90 aA & 130,33 aA \\
\hline & Outubro & 536,72 bB & $495,77 \mathrm{cB}$ & 258,40 bA \\
\hline & Novembro & 463,25 bA & $782,79 \mathrm{~dB}$ & 478,04 bA \\
\hline \multirow{4}{*}{2019} & Janeiro & 239,21 aA & 278,32 bA & 138,17 aA \\
\hline & Fevereiro & 195,27 aA & 227,30 aA & 100,77 aA \\
\hline & Março & 154,19 aA & 200,88 aA & 95,36 aA \\
\hline & Abril & 142,38 aA & 109,85 aA & 115,30 aA \\
\hline
\end{tabular}

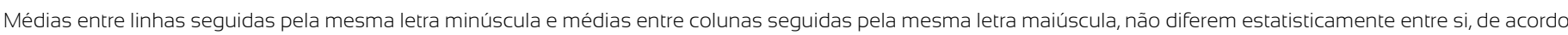
com o teste de Scott - Knott a 5\% de significância.

Conforme observado na tabela 1 , os valores de biomassa da serapilheira variaram de acordo com a variabilidade espacial em razão da composição florística, como observado em campo, e em razão do período. O maior aporte (total) no fragmento II, embora muito próximo do fragmento I, ocorreu devido à localização. Este encontra-se situado na área de maior diversidade florística da Flona, em que, Oliveira et al. (2001) explicam que a área é composta em sua maior parte por indivíduos adultos de porte elevado, sendo classificada como de alta diversidade florística.

No fragmento I foi observado uma maior abundância de indivíduos adensados, com copas fechadas, consequentemente, isto mantém um microclima ameno no interior do fragmento. Além disso, a deciduidade é influenciada entre outros fatores pela velocidade do vento, que incidirá diretamente na temperatura e umidade, em que, a princípio, seria um dos motivos pelo menor aporte de material quando comparado o fragmento II.

Ao comparar os aportes de serapilheira entre as respectivas áreas (floresta estacional semidecidual) e uma área de floresta ombrófila densa com diferentes históricos de perturbação, percebe-se números incipientes na estacional, conforme observado no trabalho de Santos
(2014), onde verificaram que a produção de serapilheira foi maior no trecho mais preservado $\left(8315 \mathrm{~kg} \mathrm{ha}^{-1}\right.$ ano ${ }^{-1} \pm$ $1495 \mathrm{~kg} \mathrm{ha}^{-1}$ ano $\left.^{-1}\right)$ do que naquele dominado pelo bambu (6770 kg ha-1 ano $\left.{ }^{-1} \pm 1122 \mathrm{~kg} \mathrm{ha}^{-1} \mathrm{ano}^{-1}\right)$, trecho esse, que passou por processo de perturbação antrópica. Já, no estudo realizado por Barbosa e Faria (2006) em duas formações florestais secundárias de floresta tropical de baixada, uma de 40 anos e outra de 20 anos, ele obteve que, a floresta em estágio avançado de regeneração (40 anos) apresentou um maior aporte total, $6900 \mathrm{~kg} \mathrm{ha}^{-1}$ ano ${ }^{-1} \pm$ $1100 \mathrm{~kg} \mathrm{ha}{ }^{-1}$ ano $^{-1}$, quando comparada a em estágio intermediário (20 anos) com $5500 \pm 500 \mathrm{~kg} \mathrm{ha}^{-1}$ ano $^{-1}$. Semelhante ao que acontece nesse estudo, onde os fragmentos mais preservados, apresentaram maior quantidade de serapilheira.

Também, Bianchi, Scoriza e Correia (2016) estimaram em um remanescente florestal de 30 ha, há 80 anos em regeneração, caracterizado como uma Floresta Estacional Semidecidual em estágio médio a avançado de regeneração, um aporte de serrapilheira de $4700 \mathrm{~kg} \mathrm{ha}^{-1} \mathrm{ano}^{-1}$, valor inferior ao estimado nessa pesquisa, o que pode estar associado a heterogeneidade ambiental e condições edafoclimáticas. 
Como pode ser observado, os três fragmentos seguiram o mesmo padrão de sazonalidade, onde a maior quantidade de material depositado sobre o piso florestal concentra-se entre os meses de setembro a novembro de 2018, o que está associado, diretamente, ao período com menor precipitação pluviométrica (Fig. 1).

Os fragmentos apresentaram maior aporte de serapilheira na estação seca, a princípio, devido ao estresse hídrico aos quais os indivíduos ficaram expostos, fazendo com que percam suas folhas em maior proporção. Observações semelhantes para diferentes áreas fitofisionômicas foram feitas por Scoriza e Piña-rodrigues (2014) e Bianchi et al. (2016) em área de Floresta Estacional Semidecidual e, Lima, Fernandes, Fernandes e Matricardi (2015) e Holanda et al. (2017) em área de Savana Estépica. Esse padrão de maior e menor deposição de serapilheira nos diferentes meses do ano está diretamente relacionado com a precipitação pluviométrica, altitude, tipo de solo, variações fitofisionômicas, dentre outros. Tais fatores corroboram com a afirmação de Selle (2007), quando descreve que esse padrão é decorrente do equilíbrio das condições climáticas, atrelado a imensa diversidade de espécies que compõe as florestas.

Tal fato foi observado por Toscan, Guimarães e Temponi (2017) ao estudar em uma reserva de Floresta Estacional Semidecidual no oeste do Paraná, região com precipitação média anual de $1800 \mathrm{~mm}$, onde estimaram uma deposição anual de $11886 \mathrm{~kg} \mathrm{ha}^{-1} \mathrm{ano}^{-1} \mathrm{com}$ os picos de deposição ocorrendo nos meses mais secos (agosto e setembro), correspondendo a $1818 \mathrm{~kg} \mathrm{ha}^{-1} \mathrm{mês}^{-1}$ e $1659 \mathrm{~kg}$ ha ${ }^{-1} \mathrm{mês}^{-1}$, respectivamente. Para os fragmentos I, II e III da Flona de Nísia Floresta, os picos de deposição ocorreram nos meses mais secos e, por sinal, com números bem inferiores (536,72 kg ha ${ }^{-1}$ mês $^{-1} ; 782,79 \mathrm{~kg} \mathrm{ha}^{-1}$ mês $^{-1}$ e 478,04 kg ha-1 mês $^{-1}$ ) quando comparado ao trabalho conduzido no Paraná por Toscan et al. (2017), porém, vale ressaltar que o presente estudo foi realizado no gradiente borda interior ( $0 \mathrm{~m}$ a $100 \mathrm{~m}$ ) de fragmentos florestais com diferentes estágios sucessionais.

Sobre deposição da serapilheira no gradiente borda e interior, verifica-se que, para os fragmentos I e II, não há diferenças estatísticas, porém, havendo apenas para o fragmento III, onde, nas distâncias entre 60 m e 100 m, há uma maior taxa de deposição $\left(1364,96 \mathrm{~kg} \mathrm{ha}^{-1} \mathrm{ano}^{-1}\right) \mathrm{e}$, da borda $(0 \mathrm{~m})$ aos $40 \mathrm{~m}$, verifica-se um aporte incipiente com apenas 608,43 kg ha-1 ano $^{-1}$ (Tabela 2).

Para o fragmento I, embora não verificado diferenças estatísticas da borda para o interior, foi observado em campo a presença de pequenas clareiras, a princípio, por ser um pouco mais madura quando comparado aos demais. Sendo que, Martins e Rodrigues (1999) explicam que a deposição de serapilheira em clareiras não é diferente de outros ambientes da floresta. No fragmento II, percebeu-se valores mais aproximados, demonstrando uma continuidade no dossel florestal que, consequentemente, vem contribuindo significativamente com a deposição de serapilheira.

Para o fragmento III, observou-se o inverso, com efeito de borda significativo nos primeiros 40 metros, retardando a recuperação florística e estrutural da vegetação. Além de que, o menor aporte para o fragmento III, é decorrente da região ter menor tempo de repouso para regeneração natural, e consequentemente ser formada por uma vegetação semiaberta, ainda não estabelecida, com árvores espaçadas e em grande parte, de porte médio.

Ratificando os números observados na tabela 2, percebe-se por meio da figura 2 que, de fato, por ser uma área mais madura e apresentar indivíduos mais velhos, com o passar do tempo alguns vão senescer, morrer, e consequentemente abrirão clareiras. Porém, esse processo de sucessão não comprometeu de forma incisiva alguns processos dinâmicos dos fragmentos, a exemplo, deposição da serapilheira. De acordo com a disposição das linhas ligadas segundo os níveis de similaridade, pôde-se observar, que a borda se agrupa com os $100 \mathrm{~m}$, indicando que são as mais semelhantes, possuindo menor distância euclidiana. Ou seja, nesse caso não há diferença da borda para o interior do fragmento, e a maior distância euclidiana da borda ocorre nos $60 \mathrm{~m}$, sendo o último conjunto de dados a entrar no agrupamento, o que pode estar relacionado com o tempo de formação dessa borda. 


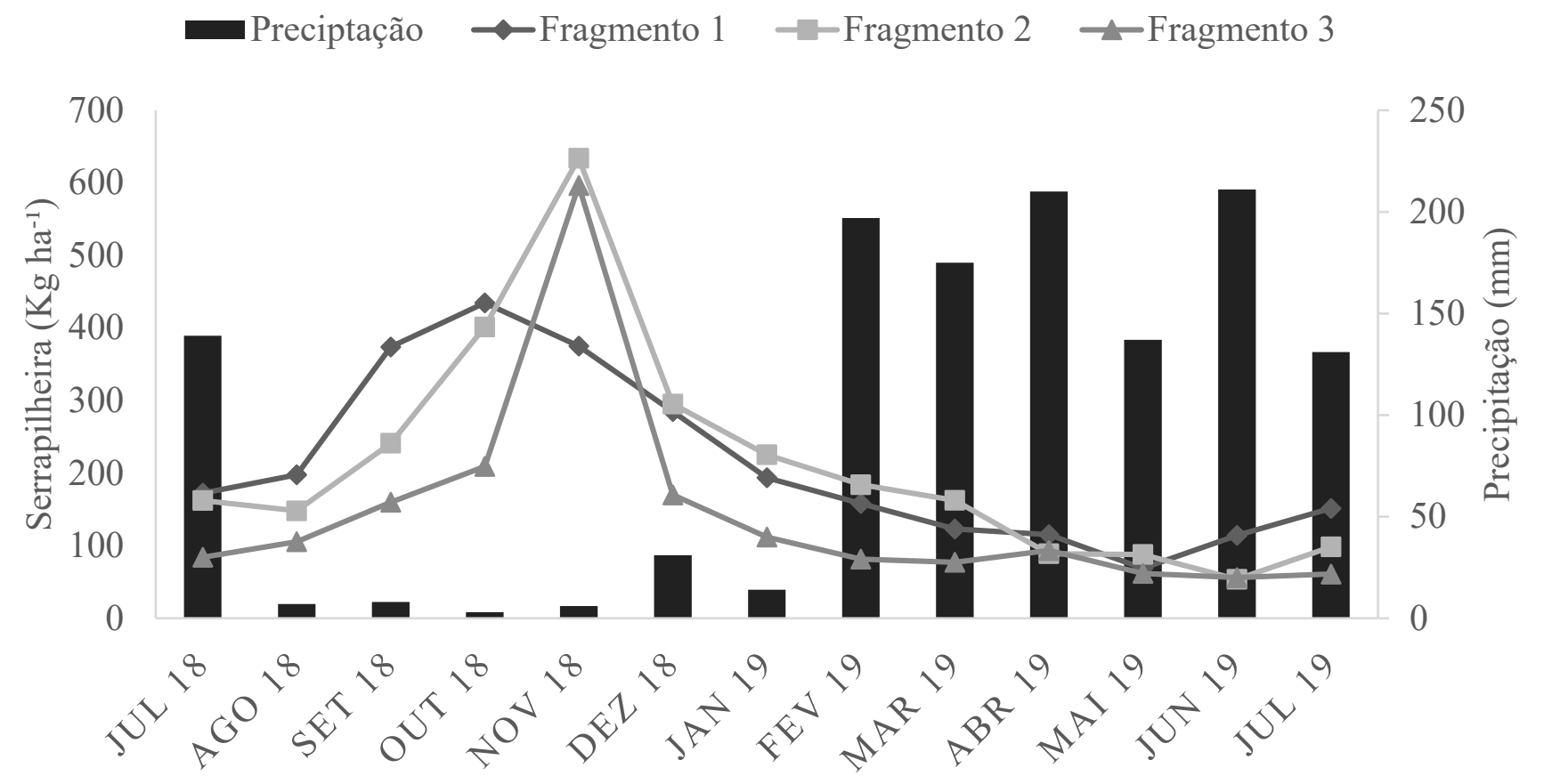

FIGURA 1. Estimativa da produção mensal de serapilheira $\left(\mathrm{kg} \mathrm{ha}^{-1}\right)$ por fragmento florestal e precipitação pluviométrica mensal na Flona de Nísia Floresta, RN.

TABELA 2. Estimativa total $\left(\mathrm{kg} \mathrm{ha}^{-1} \mathrm{ano}^{-1}\right)$ de deposição de serapilheira no gradiente borda interior $(0 \mathrm{~m}-100 \mathrm{~m})$ dos três fragmentos florestais localizados na Flona de Nísia Floresta, RN.

\begin{tabular}{cccc}
\hline $\begin{array}{c}\text { Distância da } \\
\text { borda }(m)\end{array}$ & Fragmento I & Fragmento II & Fragmento III \\
\hline 0 & $554,19 \mathrm{aA}$ & $567,79 \mathrm{aA}$ & $187,74 \mathrm{bB}$ \\
20 & $401,90 \mathrm{aA}$ & $496,54 \mathrm{aA}$ & $240,90 \mathrm{bB}$ \\
40 & $658,69 \mathrm{aA}$ & $566,35 \mathrm{aA}$ & $179,79 \mathrm{bB}$ \\
60 & $590,96 \mathrm{aA}$ & $592,30 \mathrm{aA}$ & $397,29 \mathrm{aA}$ \\
80 & $494,67 \mathrm{aA}$ & $528,32 \mathrm{aA}$ & $444,26 \mathrm{aA}$ \\
100 & $527,47 \mathrm{aA}$ & $564,26 \mathrm{aA}$ & $523,41 \mathrm{aA}$ \\
\hline
\end{tabular}

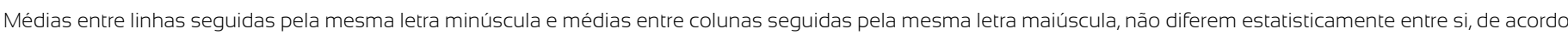
com o teste de scott - knott a 5\% de significância. 


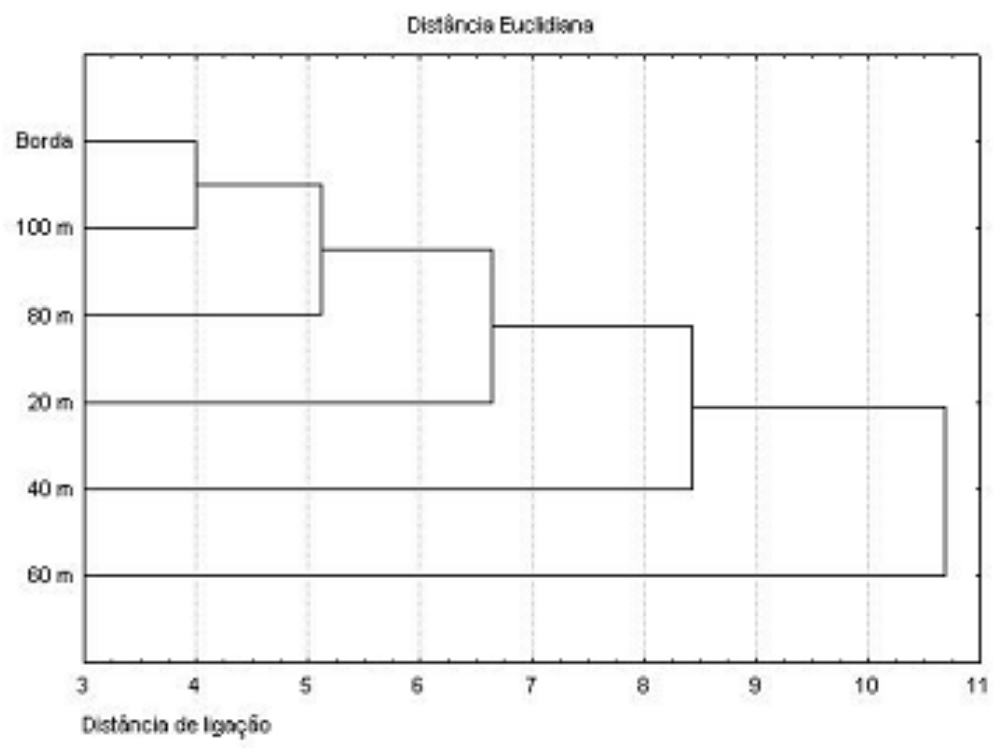

FIgURA 2. Dendrograma de similaridade da deposição de serapilheira pelo método de Ward baseado na distância euclidiana entre a borda e interior do Fragmento I, em área de Floresta Estacional Semidecidual, Nísia Floresta-RN.

Para o fragmento II, percebe-se um maior equilíbrio na deposição da serapilheira e formação dos grupos, a princípio, por ser uma área com desenvolvimento intermediário, conferindo uma maior estabilidade e recobrimento da superfície do solo (Fig. 3), consequentemente, impedindo sua exposição a fontes perturbadoras, a exemplo, processos erosivos (hídrico e eólico).

Em termos de similaridade, foi possível notar que os resultados se dividem em dois grupos, o primeiro corresponde aos valores obtidos na borda até os $80 \mathrm{~m}$ e, o segundo grupo, composto somente pelos $100 \mathrm{~m}$. O que significa que o primeiro grupo, apresenta maior semelhança, sendo a menor distância euclidiana entre os 60 $\mathrm{m}$ e $80 \mathrm{~m}$. E o segundo grupo apresenta os dados com maior dissimilaridade em relação aos demais, por ser o último conjunto de dados a se agrupar, no entanto, ainda que apresente maior distância, estatisticamente, não houve diferença significativa com relação aos demais.

Diferentemente ao que ocorreu para os fragmentos I e II, no fragmento 3, a deposição da serapilheira ocorreu de forma não monotônica (Fig. 4), havendo uma deposição desigual no gradiente borda interior, que, a curto e longo prazo, pode comprometer diretamente, serviços ecossistêmicos, retardando processos dinâmicos de renascimento e estabelecimento das espécies vegetais e, indiretamente, a fauna.

Observou-se no gráfico que há formação de dois grupos, o primeiro mostra uma maior proximidade da borda com os $40 \mathrm{~m}$ iniciais, e o segundo grupo vai dos 20 $\mathrm{m}$ aos $100 \mathrm{~m}$, sendo a menor distância euclidiana entre os $60 \mathrm{~m}$ e $80 \mathrm{~m}$. Ou seja, tem-se uma grande distinção da borda para o interior do fragmento, afirmando assim, a atuação do efeito de borda. Conforme descreveu Laurance et al. (2006) e Putz, Groeneveld, Alves, Metzger e Huth (2011), nas bordas dos fragmentos podem ser observadas uma maior abertura do dossel, consequentemente, maior temperatura e maior incidência de luminosidade e, essas condições podem estar atuando como regulador do desenvolvimento de espécies exigentes em sombra, o que acaba levando esses indivíduos a morte, permanecendo aqueles que tem preferência por uma maior incidência de luz e vento. 


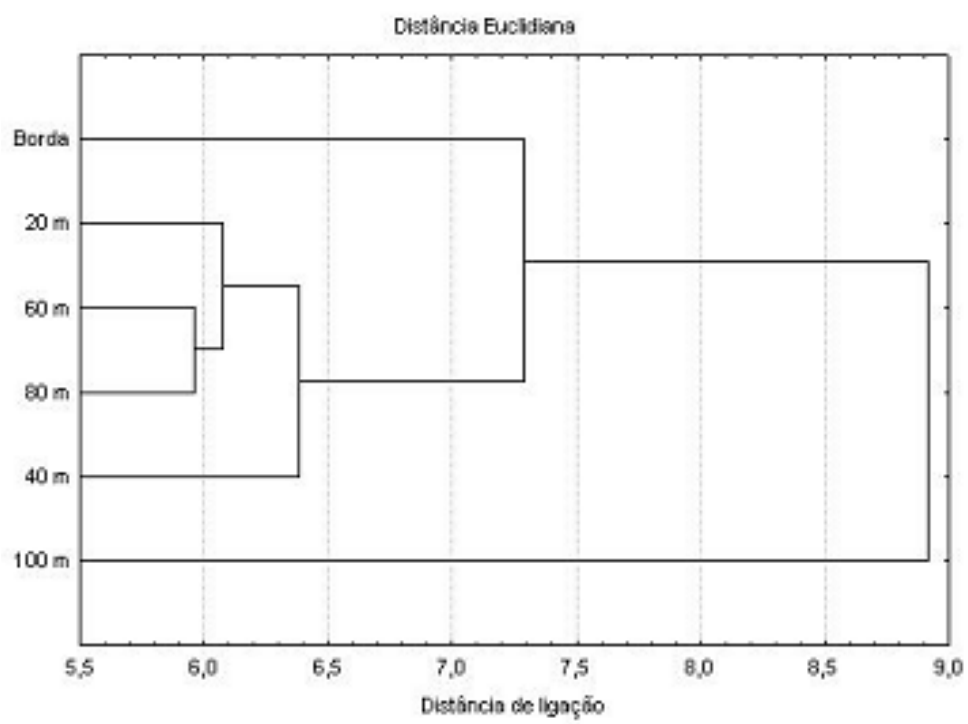

FIgURA 2. Dendrograma de similaridade da deposição de serapilheira pelo método de Ward baseado na distância euclidiana entre a borda e interior do Fragmento II, em área de Floresta Estacional Semidecidual, Nísia Floresta-RN.

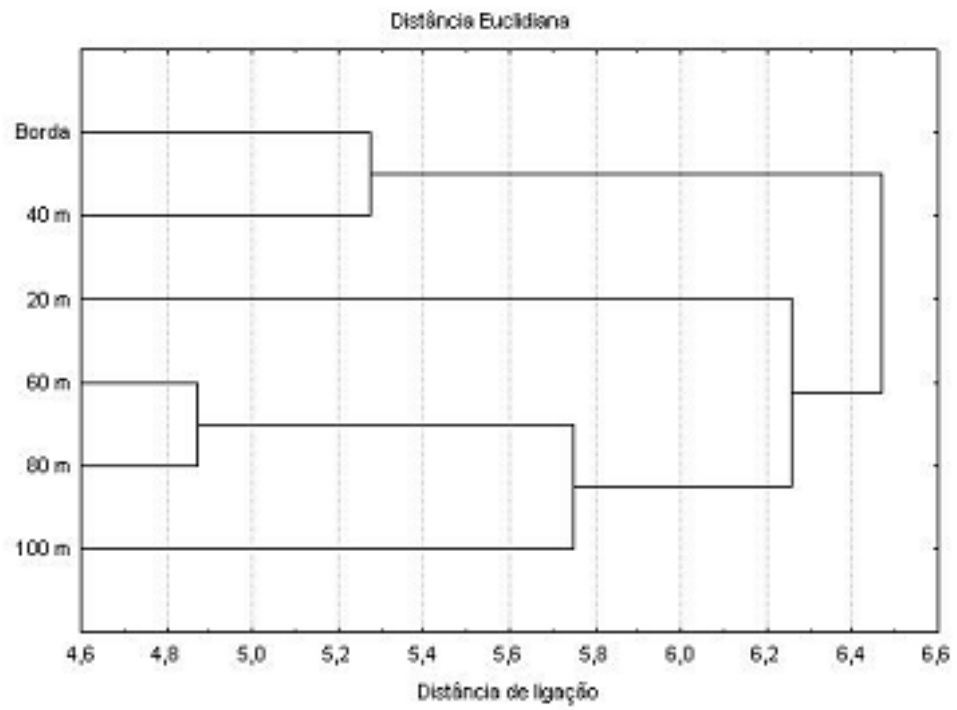

FIGURA 3. Dendrograma de similaridade da deposição de serapilheira pelo método de Ward baseado na distância euclidiana entre a borda e interior do Fragmento III, em área de Floresta Estacional Semidecidual, Nísia Floresta-RN. 
Por outro lado e, contrapondo alguns números apresentados no presente trabalho, Dick (2011), ao avaliar a influência do efeito de borda na deposição de serapilheira em três fragmentos de Floresta Estacional Decidual com diferentes tamanhos, verificou que no fragmento três (maior área) houve uma maior deposição de material na borda em relação ao interior e, para os fragmentos I e II houve maior deposição no interior, destacando que isso pode estar associado a situação de degradação e alterações da estrutura desses fragmentos.

\section{CONCLUSÕES}

A borda de fragmentos florestais em estágio inicial de sucessão tende a depositar menor quantidade de serapilheira no piso florestal, comprometendo diretamente fatores abióticos e bióticos nas florestas. O tempo de repouso é capaz de promover ao ambiente uma recuperação de boa parte das suas relações ecológicas, ainda que necessitem de futuras intervenções para melhorar as condições do meio. $\mathrm{O}$ aporte de serapilheira teve comportamento sazonal apresentando picos de produção no período seco e queda brusca no volume no período chuvoso, indicando que a pluviosidade atua como agente regulador desse processo.

\section{REFERÊNCIAS}

Alvares, C. A., Stape, J. L., Sentelhas, P. C., Gonçalves J. L. M., \& Sparovek G. (2013). Köppen's climate classification map for Brazil. Meteorologische Zeitschrift, 22(6), 711-728. doi: 10.1127/09412948/2013/0507.

Barbosa, J. H. C., \& Faria, S. M. (2006). Aporte de serrapilheira ao solo em estágios sucessionais florestais na Reserva Biológica de Poço das Antas, Rio de Janeiro, Brasil. Rodriguésia, 57(3),461-476. doi: 10.1590/2175-7860200657306

Barreto, P. A. P., Gama-Rodrigues, E. F., Gama-Rodrigues; A. C., Barros, N. F., \& Fonseca, S. (2014). Atividade, carbono e nitrogênio da biomassa microbiana em plantações de eucalipto, em uma sequência de idades. Revista Brasileira de Ciência do Solo, 32(2), 611- 619. doi:10.1590/S0100-06832008000200016

Bianchi, M. O., Scoriza, R. N., \& Correia, M. E. F. (2016). Influência do clima na dinâmica de serapilheira em uma floresta estacional semidecidual em Valença, RJ, Brasil. Revista Brasileira de Biociências, 14(2), 97-101.
Blumenfeld, E. C., Santos, R. F., Thomaziello, S. A., \& Ragazzi, S. (2016). Relações entre tipo de vizinhança e efeitos de borda em fragmento florestal. Ciência Florestal, 26(4), 1301-1316. doi:10.5902/1980509825150

Conceição, P. C., Amado, T. J. C., Mielniczuk, J., \& Spagnollo, E. (2005). Qualidade do solo em sistemas de manejo avaliada pela dinâmica da matéria orgânica e atributos relacionados. Revista Brasileira de Ciência do Solo, 29(5), 777-788. doi: 10.1590/S010006832005000500013

Cunha Neto, F. V., Leles, P. S. S., Pereira, M. G., Bellumath, V. G. H., \& Alonso, J. M. (2013). Acúmulo e decomposição da serapilheira em quatro formações florestais. Ciência Florestal, 23(3), 379-387. doi: 10.5902/1980509810549

Dick, G. (2011). Deposição de Serrapilheira como Bioindicador em Fragmentos de Floresta Estacional Decidual. Graduação em Engenharia Florestal, Universidade Federal de Santa Maria, Frederico Westphalen, RS, Brasil.

Franco, A. A., \& Campello, E. F. C. (1997). Importância da qualidade da serrapilhiera na sucessão vegetal em áreas de recuperação na Amazônia. São Carlos, Brasil: Empresa Brasileira de Pesquisa Agropecuária.

Holanda, A. C., Feliciano, A. L. P., Marangon, L. C., Santos, M. S., Melo, C. L. S. M. S., \& Pessoa, M. M. L. (2010). Estruturas de espécies arbóreas sob efeito de borda em um fragmento de floresta estacional semidecidual em Pernambuco. Revista Árvore, 34(1), 103-114. doi: 10.1590/S0100-67622010000100012

Holanda, A. C., Feliciano, A. L. P., Freire, F. J., Souza, F. Q., Freire, S. R. O., \& Alves, A. R. (2017). Aporte de serapilheira e nutrientes em uma área de Caatinga. Ciência Florestal, 27(2), 621-633. doi: $10.5902 / 1980509827747$

Instituto Brasileiro de Florestas [IBF] (2014). Mata Atlântica. Recuperado de http://www.ibflorestas.org.br. 15 abr. 2018.

Laurance, W. F., Nascimento, H. E. M., Laurace, S. G., Andrade, A., Ribeiro, J. E. L. S., Giraldo, J. P., Lovejoy, T. E., Condit, R., Chave, J., Harms, K. E. D., \& Angelo, S. (2006). Rapid decay of tree-community composition in Amazonian forest fragments. Proceedings of the National Academy of Sciences, 103(50), 19010-19014. doi: 10.1073/pnas.0609048103

Lima, R. P., Fernandes, M. M., Fernandes, M. R. M., \& Matricardi, E. A. T. (2015). Aporte e decomposição da serapilheira na Caatinga no Sul do Piaui. Floresta e Ambiente, 22(1), 42-49. doi: 10.1590/21798087.062013

Martins, S. V., \& Rodrigues, R. R. (1999). Produção de serapilheira em clareiras de uma floresta estacional semidecidual no município de Campinas, SP. Brazilian Journal of Botany, 22(3), 405-412. doi: 10.1590/S0100-84041999000300009 
Ministério do Meio Ambiente (2012). Plano de Manejo da Floresta Nacional de Nísia Floresta, Instituto Chico Mendes de Conservação da Biodiversidade- ICMBio. Nísia Floresta, Brasília, Brasil.

Oliveira, Z. L., Santos Júnior, R. C. B., \& Feliciano, A. L. P., Marangon, L. C. \& Carvalho, A. J. E. (2001). Levantamento florístico e fitossociológico de um trecho de Mata Atlântica na estação florestal experimental de Nísia floresta - RN. Brasil Florestal, 71, 22-29.

Putz, S., Groeneveld, J., Alves, L. F., Metzger, J. P., \& Huth, A. (2011). Fragmentation drives tropical forest fragments to early successional states: a modelling study for Brazilian Atlantic forests. Ecological Modelling, 222(12), 1986-1997. doi: 10.1016/j.ecolmodel.2011.03.038

Radam Brasil (1981). Geologia, geomorfologia, pedologia, vegetação e uso potencial da terra. Rio de Janeiro, Brasil.

Ribeiro, M. S. L. (2008). Efeitos de borda sobre a vegetação e estruturação populacional em fragmentos de Cerradão no Sudoeste Goiano, Brasil. Acta Botanica Brasilica, 22(2), 535-545. doi: 10.1590/S0102-33062008000200020

Santana, J., \& Souto, J. S. (2011). Produção de serapilheira na Caatinga da região semiárida do Rio Grande do Norte, Brasil. Idesia, 29(2), 87-94. doi:10.4067/S0718-34292011000200011.

Santos, A. R. (2014). Produção, estoque e nutrientes da serapilheira em Floresta Ombrófila Densa do Parque Estadual das Fontes do Ipiranga, São Paulo, Brasil. Dissertação em Botânica, Instituto de Botânica da Secretaria de Estado do Meio Ambiente, São Paulo.

Scoriza, R. N., \& Piña-Rodrigues, F. C. M. (2014). Influência da precipitação e temperatura do ar na produção de serapilheira em trecho de floresta estacional em Sorocaba, SP. Revista Floresta, 44(4), 687-696. doi: 10.5380/rf.v44i4.34274
Selle G. L. Ciclagem de nutrientes em ecossistemas florestais. (2007). Bioscience Journal, 23(4), 29-39.

Toscan, M. A. G., Guimarães, A. T. B., \& Temponi, L. G. (2017). Caracterização da produção de serapilheira e da chuva de sementes em uma reserva de floresta estacional semidecidual, Paraná. Ciência Florestal, 27(2), 415-427. doi: 10.5902/1980509827725

Viana, V. M., Tabanez, J. A., \& Martins, J. L. A. (1992). Restauração e manejo de fragmentos florestais. Congresso nacional sobre essências nativas (pp. 400-406). Campos do Jordão, Brasil. Instituto Florestal/Secretaria do Meio Ambiente.

\section{Manuscrito recebido em 28 de maio de 2020}

Aceito em 01 de dezembro de 2020

Publicado em 22 de dezembro de 2021

Este documento se debe citar como:

Câmara, Y. B., Holanda, A. C., Costa, E. J. P. (2021). Aporte de serapilheira na borda de fragmentos florestais em diferentes estágios sucessionais na Mata Atlântica do Rio Grande do Norte, Brasil. Madera y Bosques, 27(2), e2722179. doi: 10.21829/myb.2021.2722179

Madera y Bosques pelo Instituto de Ecología, A.C. é distribuída sob uma Licença Internacional Creative Commons Atribuição-NãoComercial ShareAlike 4.0. 